\title{
Effects of flooring and rearing system on hoof health of dairy cows in some selected areas of Bangladesh
}

\author{
MA Rahman* ${ }^{1}$, MA I mtiaz², M Ahaduzzaman ${ }^{1}, K^{2}$ Ghosh $^{3}$, AA Masud ${ }^{3}$, S Chowdhury ${ }^{4}$, S Sikder $^{1}$ \\ ${ }^{1}$ Department of Medicine and Surgery, ${ }^{2}$ Department of Physiology, Biochemistry and Pharmacology, \\ ${ }^{3}$ Department of Microbiology, ${ }^{4}$ Department of Pathology and Parasitology, Chittagong Veterinary and Animal \\ Sciences University, Khulshi 4225, Chittagong, Bangladesh
}

\begin{abstract}
A survey was conducted to explore prevalence and risk factors of diverse hoof disorders on dairy cows at Chittagong and Patuakhali, Bangladesh from June 2012 to February 2013. About 2103 cows were examined from where 497 cases identified having fissure (37\%), crack (19\%), partially broken (19\%), swollen hoof (16\%) and multiple disorders (9\%) in backyard dairy cows whereas 37\%, 17\%, 20\%, 20\% and $6 \%$ in commercial cows, respectively. Significantly higher prevalence $(p<0.05)$ was recorded in cows reared under concrete floor $(68.4 \%)$ compared to brick $(13.27 \%)$ and concrete with rubber bedding (18.3\%). Other major conventional risk factors were season, age, milk yield and washing practiced on floor though the results were not significant $(p>0.05)$. The study has remarked frequency of hoof diseases in the survey areas along with factors causing risk to dairy cows.
\end{abstract}

Key words: flooring system, hoof health, prevalence and risk factors

Bangladesh Animal Husbandry Association. All rights reserved. Bang. J. Anim. Sci. 2014.43 (2): 132-137

\section{I ntroduction}

Hoof is a hard and horny covering of the ends of digits. Diseases at hoof considered as an important health hazard having a negative effect on the welfare of dairy cows (Bergsten 2004). It has a tremendous impact directly on cattle and indirectly on economic profit in dairy production (Hernandez et al. 2005). Avulsion of hoof, sloughed-off, cracked, fissured, broken, luxated hooves are frequent disorders of hooves alarming the hoof health. Different localized and systemic diseases like Foot and Mouth Disease (FMD), foot rot, wound, arthritis, laminitis, bed sore, abscess, milk fever, downer's cow syndrome and physical trauma predispose cow towards abnormalities of hooves leading to lameness and recumbancy of animal (Cook et al. 2005). In addition, high yielding dairy cows, over-nourished and heavy weight cows which are reared intensively on concrete floor (Sogstad et al. 2005) are considered as risk factors.

Lameness due to hoof disorder has been identified as a major welfare determinant in cattle because of discomfort and pain (Offer et al. 2000). More than $60 \%$ lameness in cattle is caused by disorders such as sole ulcers, heel erosion, sole bruising and white line separation and under run (double) soles. There are also some other intrinsic risks for lameness including season, gestation, stage of lactation (Green et al. 2002), previous disease and parity (Hirst et al. 2002). All these hoof disorders and lesions have a direct or indirect effect on the dermis (corium) of hoof and are associated with laminitis (Belge et al. 2005). Many sequestrations such as reduced conception rate, ovarian activity, premature culling, occasional mortality and increased calving interval are associated with lameness (Knight 2001). Lame cows show more susceptibility to mastitis, the most significant economic disease of dairy animals leading to poor production.

There are indiscriminate researches on hoof health related welfare (Enting et al. 1997), production, reproduction and diseases in high yielding dairies (Green et al. 2002, Hirst et al. 2002, Hedges et al. 2001, Knight 2001, Vokey et al. 2001). However, a limited information is available on hoof disorders of cross-bred cattle in our country. The actual prevalence is controversial and management dependents rely on geography. Therefore, the present study was anticipated to explore prevalence of hoof 
Flooring and rearing system on hoof health of cow

disorders and to detect associated risk factors leading to hoof diseases of dairy cows at Chittagong and Patuakhali districts of Bangladesh.

\section{Materials and methods}

This study was conducted on commercial and backyard dairy cows of Chittagong metropolitan area (CMA), Patiya upazila of Chittagong and Bauphal upazila of Patuakhali district in Bangladesh. About 2103 dairy cows belonging to 87 farms (backyard farms) kept under consideration where farms were selected by random sampling technique. Among all cases, cross ( 1557 cows) and local (446 cows) breeds of dairy cows were examined. Cows, under commercial farming system cent-percent were cross of local with exotic and backyard system mostly of indigenous.

Questionnaire was designed to comprise mostly closed ended (categorical) questions according to (Thrusfield 2005). Repeated questioning was performed over farmers, observation of cows and taking records from register book. Survey was undertaken from March 2012 to February 2013. Animal level data were recorded including breed, age, sex, body condition, posture, physical status, parity, milk yield per day, major diseases, diseases relevant to hoof, type of floor, rearing system, washing system, housing pattern, floor (katcha/ dirt/ muddy/ brick/ concrete/ rubber bedded), rearing system (intensive/ semiintensive/ free-range) as well as system of grazing or zero-grazing. Clinical examinations findings were noted down accordingly.

Diagnosis was made on the basis of clinical history, closed and careful examination of hooves scientifically. General attitude (alertness/ dullness/ depression), body condition (Cachectic/ poor/ fair/ good/ fat/ over fat) and posture gait (normal/ defective) were cautiously inspected by distant inspection (Radostits et al. 2000). Closed examinations of hooves were identified major disorders like fissure, crack, partially broken, avulsion, overgrowth and sole ulcer (Figure 1) as well as diseases i.e. foot and mouth disease, foot rot, laminitis, physical injury, wounds, abscess, myiasis, arthritis, bed sore.
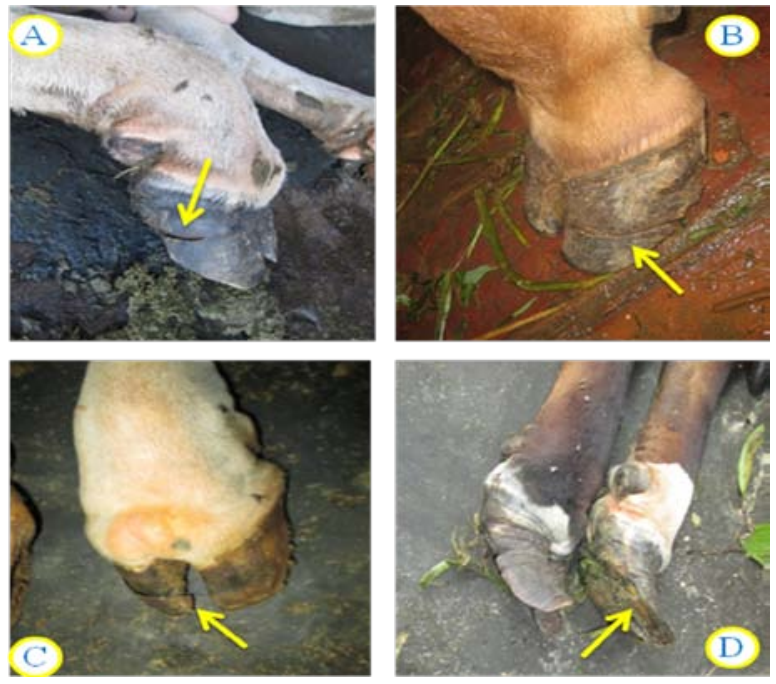

Figure 1. Hoof disorders: cracked hoof (A), partially broken hoof (B), avulsion of hoof (C) and sole ulcer $(D)$

Data were entered into MS excel (Microsoft office excel 2007, USA). Descriptive analysis was performed by STATA version 12.1 (STATA Corporation, USA) to estimate the association between a categorical explanatory variable with outcome, and then Chi square $\left(x^{2}\right)$ test was performed. An association was regarded as significant if $p<0.05$.

\section{Results}

In the present study, 497 cases were identified from 2103 different examined cows where cows were recorded from Shikalbaha area of Patiya (472), Bauphal (22) and Chittagong Metropolitan Area (3). Among them 37\%, 20\%, 19\%, 17\% and $7 \%$ cows suffered from broken, swollen, cracks and multiple problems, respectively. Three age groups were categorized accordingly $<5$ years ( 81 cows), within 5 to 8 years ( 350 cows) and $>8$ years ( 66 cows). It was found that, only rearing system of cows was significantly associated $(p<0.05)$ with different hoof disorders. Details of the relationship with their $p$ values are illustrated in Table 1.

The present study revealed that prevalence of hoof disorders was maximum in cows reared under intensive housing (98\%) compared to semi-intensive $(2 \%)$. Moreover, partially broken $(60 \%)$ hooves were significantly $(p<0.05)$ higher in semi-intensive cows whereas fissured (37\%) hooves were mostly prevalent in intensive cows. 
Rahman et al. (2014) Bang. J. Anim. Sci. 43 (2): 132- 137

Table 1. Hoof disorders with different explanatory variables (using $x^{2}$ test)

\begin{tabular}{|c|c|c|c|c|c|c|c|c|}
\hline \multirow[t]{2}{*}{ Variables } & \multirow[t]{2}{*}{ Level } & \multicolumn{6}{|c|}{ Number of hoof disorders } & \multirow[t]{2}{*}{$p$ value } \\
\hline & & Crack & Partially Broken & Fissure & Swollen & Multiple problems & Total & \\
\hline \multirow[t]{2}{*}{ Farm type } & Backyard & $21(19)$ & $21(19)$ & $40(37)$ & $17(16)$ & $10(9)$ & $109(21.93)$ & 0.82 \\
\hline & Commercial & $66(17)$ & $76(20)$ & $143(37)$ & $76(20)$ & $27(6)$ & $388(78.06)$ & \\
\hline \multirow[t]{3}{*}{ Season } & Autumn & $37(17)$ & $41(19)$ & 79 (37) & $40(19)$ & $16(8)$ & $213(42.86)$ & 0.99 \\
\hline & Rainy & $18(18)$ & $19(19)$ & $38(38)$ & $19(19)$ & $6(6)$ & $100(20.12)$ & \\
\hline & Winter & $32(17)$ & $37(20)$ & $66(36)$ & $34(18)$ & $15(8)$ & $184(37.02)$ & \\
\hline \multirow{2}{*}{$\begin{array}{l}\text { Rearing } \\
\text { system }\end{array}$} & Intensive & $85(17)$ & $91(19)$ & $182(37)$ & $92(19)$ & $37(8)$ & $487(98)$ & 0.01 \\
\hline & Semi-intensive & $2(20)$ & $6(60)$ & $1(10)$ & $1(10)$ & 0 & $10(2)$ & \\
\hline \multirow[t]{3}{*}{ Type of floor } & Brick & $13(20)$ & $13(20)$ & $26(39)$ & $12(18)$ & 2 (3) & $66(13.28)$ & 0.29 \\
\hline & Concrete & $53(16)$ & $72(21)$ & $129(38)$ & $60(18)$ & $26(8)$ & $340(68.4)$ & \\
\hline & Combined & $21(23)$ & $12(13)$ & $28(31)$ & $21(23)$ & $9(10)$ & 91 (18.31) & \\
\hline Floor & SID & $8(15)$ & $10(19)$ & $19(35)$ & $13(24)$ & $4(7)$ & $54(10.85)$ & 0.86 \\
\hline \multirow[t]{2}{*}{ washing } & BID & 55 (19) & $54(19)$ & $111(38)$ & $50(17)$ & $19(7)$ & $289(58.15)$ & \\
\hline & TID & $24(16)$ & $33(21)$ & $53(34)$ & 30 (19) & $14(9)$ & $154(31)$ & \\
\hline
\end{tabular}

*SID, single in a Day; BID, twice in a Day; TID, trice in a Day; figures in the parentheses indicate the percent values

It was found that diseases of hooves were mostly prevailed at 6-8 years aged cows. Fissured hooves were more regardless of the age where cracked hooves were mostly in older cows though the results were insignificant $(p>0.05)$ (Figure 2$)$. On the other hand, the highest $72.5 \%$ hoof disorders were observed in cows having 10-14 liter milk yield per day ( $p>0.05$ ) (Figure 3 ).

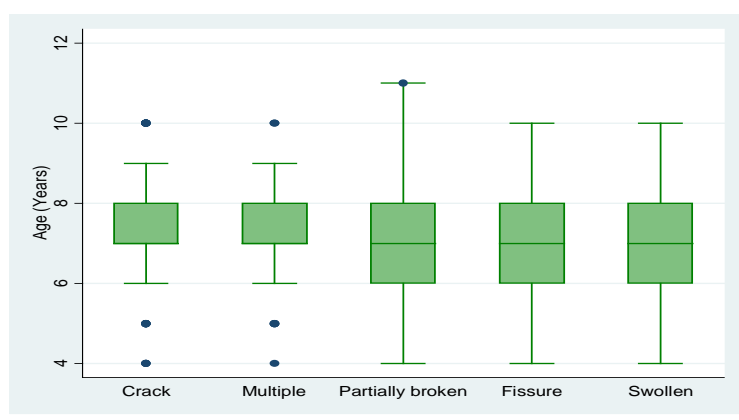

Figure 2. Age specific prevalence of hoof disorders

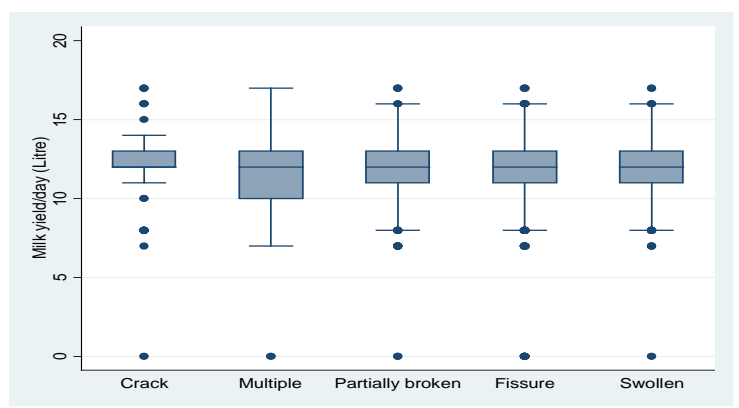

Figure 3: Prevalence of hoof disorders based on milk yield

\section{Discussion}

Our study revealed 497 various hoof diseases and disorders case from 2103 commercial and backyard dairy cows on which prevalence of cracks were $17 \%$ and $19 \%$, respectively that were almost similar to the findings of Bielfeldt et al. (2004) who reported as $15.7 \%$ to $17.1 \%$ in Swiss dairy cows. A higher rete of $72 \%$ hoof abnormality was reported by Manske et al. (2002). Moreover, wide varieties of lower rates were published as $7.9 \%$ in Germany by Schopke et al. (2013), 3.5\% in Ethiopia by Sulayeman and Fromsa (2012), $0.6 \%-39.9 \%$ in Netherland by van der Waaij et al. (2005). Intensively reared cows showed higher risk to suffer from different hoof disorders compared to grazing cows (Haskell et al. 2006; Hultgren and Bergsten 2001). Among the disorders, prevalence of fissure was higher (37\%) than others i.e. van der Waaij et al. (2005) recorded $0.13-0.91 \%$ fissure in Denmark. In addition, prevalence of swollen hooves (16$20 \%$ ) were inconsistent with the findings of other researcher (Bielfeldt et al. 2004; Sulayeman and Fromsa 2012; Hedges et al. 2001), whereas lower frequency of $5.5 \%$ and $5 \%$ swollen hooves were reported by Schopke et al. (2013) and Clarkson et al. (1996), respectively. Moreover, 19-20\% cows had partially broken hooves which were agreed by Bielfeldt et al. 2004 in Switzerland. Higher rates were reported by Vanegas et al. (2006) (60\%) in US and lower 
rates were analyzed by Clarkson et al. (1996) (8\%) in UK and Schopke et al. (2013) (7.1\%) in Germany. Finally, a range of $6-9 \%$ cows were found to have more than one hoof problem under this study. Variable sizes of the study population, climatic effect and floor type of the study farms and genetic make-up of different breeds might reflect the variations of results.

Present study noticed that commercial dairy cows reared in intensive housing showed significantly higher prevalence of hoof disorders compared to free-range or semi-intensive which is disagreed by Somers et al. (2003) where higher (63\%) prevalence in pasture grazing than lower $37.4 \%$ in housed animals. On other hand, Amory et al. (2006) and van der Waaij et al. (2005) recorded $7.5 \%$ and $21.2 \%$ digital dermatitis as hoof lesions in Netherland. The type of floor and flooring materials used in different countries might have variable effects on creating hoof disorders. This study established $13.28 \%$ prevalence on cows housed on bricked floor and $68.4 \%$ on concrete though lower prevalence was reported by Somers et al. (2003) (20.1\%) and Bergsten (2001) $(10.21 \%)$. Additionally, $18.31 \%$ prevalence on concrete floor having rubber bedding was revealed by this study was much higher than the findings of Bergsten (2001).

The cows identified having hoof diseases all were cross of local whereas Sulayeman and Fromsa (2012) reported $3.8 \%$ prevalence in both local and Holstein Friesian cows with $1.6 \%$ in cross breeds. The study also showed a higher $70.4 \%$ prevalence in the cow of 5-8 years old with lower in the cows $<5$ years $(16.3 \%)$ and $>8$ years (13.3\%) while Sulayeman and Fromsa (2012) published a higher $4 \%$ prevalence in the cows of $>2$ years and a lower $2.2 \%$ in $<2$ years old cows. In addition, Talukdar et al. (2005) found $2.11 \%$ and $2.82 \%$ prevalence in calves and heifer cow, respectively in Bangladesh. Cows having 10-14 liter of milk production were found more prone to hoof disorders $(72.5 \%)$ compared to $19.1 \%$ in $<10$ liter and $8.45 \%$ in $>14$ liter milk yielding cows and the findings were agreed by Hultgren et al. (2004). Moreover, Shearer and Amstel (2000) recorded $11.4 \%, 13.3 \%$ and $8.1 \%$ in the cows with $1^{\text {st }}, 2^{\text {nd }}$ and subsequent lactations. High yielding cows suffer from more disorders might be due to inadequate nutrient supply and management (Mulling et al. 2006).
Seasonal prevalence of the study showed $17 \%$ cracked, $19 \%$ partially broken, $37 \%$ fissured, $19 \%$ swollen and $8 \%$ having multiple disorders during autumn while Manske et al. (2002) and Hedges et al. (2001) reported overall prevalence of $5.1 \%$ in Sweden and $70 \%$ in UK respectively. In addition, hoof disorders were found as crack $(18 \%)$, partially broken $(19 \%)$, fissure $(38 \%)$, swollen (19\%) and multiple disorders (6\%) whereas Clarkson et al. (1996) recorded $20 \%$ and $18.6 \%$ in US and UK accordingly. Furthermore, prevalence at winter was noticed as crack $(17 \%)$, partially broken $(20 \%)$, fissure (36\%), swollen hooves (18\%) and multiple problems (8\%) though Clarkson et al. (1996) published $80 \%$ and $25 \%$ in US and UK consequently. Geographical distribution of animals might be adapted to a particular climate favorable to avoid unnecessary sufferings by seasonal variations. Further extensive studies are needed to confirm the present status of hooves, to investigate the specific causal agents responsible for alteration of hoof health and economic losses caused by hoof disorders.

\section{Conclusion}

The hoof disorders were mostly found in the cows reared commercially under intensive housing where autumn season, concrete floor, aging and high milk yield were found most probable risk factors contributing to do these. The study addresses the prevalence and factors causing hoof diseases to the farmers, attendants as well as the veterinarians of Bangladesh so that they can take necessary steps for better welfare and management of cows and profit of the farmers.

\section{Acknowledgement}

Authors are grateful to the owners and veterinary clinicians, especially Dr. Md. Habibur Rahman Khan, Upazila Livestock Officer, Upazila Veterinary Hospital, Bauphal, Patuakhali for his cordial cooperation participated in this research.

\section{References}

Amory JR, Kloosterman P, Barker ZE, Wright J L, Blowey RW, Green LE (2006). Risk factors for poor locomotion in dairy cattle in cubicle housing on nineteen farms in the Netherlands. Journal of Dairy Science, 89: 1509-1515. 
Belge A, Bakir B, Gonenci R, Ormanci S (2005). Subclinical laminitis in dairy cattle: 205 selected cases. Turkish Journal of Veterinary and Animal Sciences, 29: 9-15.

Bergsten C (2001). Effects of conformation and management system on hoof and leg diseases and lameness in dairy cows. Veterinary Clinics of North America: Food Animal Practice, 17: 1-23, V.

Bergsten C (2004). Lameness and claw lesions as influenced by stall environment and cow comfort, published in IVIS with the permission of the WBC, Québec, Canada.

Bielfeldt J, Tolle K-H, Badertscher R, Krieter J (2004). Investigation of claw health of dairy cows in Switzerland, Commission on Animal Management and Health.

Clarkson MJ, Downham DY, Faull WB, Hughes JW, Manson FJ, Merritt JB, Murray RD, Russell WB, Sutherst JE, Ward WR (1996). Incidence and prevalence of lameness in dairy cattle. Veterinary Record, 138: 563567.

Cook NB, Bennett TB, Nordlund KV (2005). Monitoring indices of cow comfort in freestall-housed dairy herds. Journal of Dairy Science, 88: 3876-3885.

Enting $\mathrm{H}$, Kooij D, Diikhuizen AA, Huirne RBM, Noordhuizen-Stassen EN (1997). Economic losses due to clinical lameness in dairy cattle. Livestock Production Science, 49: 259-267.

Green LE, Hedges VJ, Schukken YH, Blowey RW, Packington AJ (2002). The impact of clinical lameness on the milk yield of dairy cows. J ournal of Dairy Science, 85: 2250-2256.

Haskell MJ, Rennie LJ, Bowell VA, Bell MJ, Lawrence $A B$ (2006). Housing system, milk production and zero-grazing effects on lameness and leg injury in dairy cows. J ournal of Dairy Science, 89: 4259-4266.

Hedges J, Blowey RW, Packington AJ, O'Callaghan CJ, Green LE (2001). A longitudinal field trial of the effect of biotin on lameness in dairy cows. Journal of Dairy Science, 84: 19691975.

Hernandez JA, Garbarino EJ, Shearer JK, Risco CA, Thatcher WW (2005). Comparison of the calving-to-conception interval in dairy cows with different degrees of lameness during the prebreeding postpartum period. Journal of the American Veterinary Medical Association, 227: 1284-1291.
Hirst WM, Murray RD, Ward WR, French NP (2002). A mixed-effects time-to-event analysis of the relationship between firstlactation lameness and subsequent lameness in dairy cows in the UK. Preventive Veterinary Medicine, 54: 191201.

Hultgren J, Bergsten C (2001). Effects of rubberslatted flooring system on cleanliness and foot health in tied dairy cows. Preventive Veterinary Medicine, 52: 75-89.

Hultgren J, Manske T, Bergsten C (2004). Associations of sole ulcer at claw trimming with reproductive performance, udder health, milk yield and culling in Swedish dairy cattle. Preventive Veterinary Medicine, 62: 233-251.

Knight CH (2001). Lactation and gestation in dairy cows: flexibility avoids nutritional extremes. Cambridge J ournals- Proceedings of the Nutrition Society, 60: 527-37.

Manske T, Hultgren J, Bergsten C (2002). Prevalence and interrelationships of hoof lesions and lameness in Swedish Dairy cows. Preventive Veterinary Medicine, 54: 247-263.

Mulling CKW, Green L, Barker Z, Scaife J, Amory JR, Speijers M (2006). Risk factors associated with foot lameness in dairy cattle and a suggested approach for lameness reduction, published in the IVIS website with the permission of the congress organizers.

Offer JE, Logue DN, McNulty D (2000). Observations of lameness, hoof conformation and development of lesions in dairy cattle over four lactations. Veterinary Record, 147: 105-109.

Radostits OM, Gay CC, Blood DC, Hinchcliff KW (2000). Clinical examination and making a diagnosis, In: Veterinary Medicine, A textbook of the diseases of cattle, sheep, pigs, goats and horses, $9^{\text {th }}$ edn, W B Saunders, P. 3-40.

Schopke K, Weidling S, Pijl R, Swalve HH (2013). Relationships between bovine hoof disorders, body condition traits and test-day yields. Journal of Dairy Science, 96: 679689.

Shearer JK, Amstel V (2000). Lameness in Dairy Cattle. Simulation system (RUSITEC). Archives of Animal Nutrition, 55: 371-376. 


\section{Flooring and rearing system on hoof health of cow}

Sogstad AM, Fjeldaas T, Osteras O, Plym Forshell K (2005). Prevalence of claw lesions in Norwegian dairy cattle housed in tie stalls and free stalls. Preventive Veterinary Medicine, 70: 191-209.

Somers J GCJ, Frankena K, Noordhuizen-Stassen EN, Metz JHM (2003). Prevalence of Claw Disorders in Dutch Dairy Cows Exposed to Several Floor Systems. Journal of Dairy Science, 86: 2082-2093.

Sulayeman M, Fromsa A (2012). Lameness in Dairy Cattle: Prevalence, Risk Factors and Impact on Milk Production. Global Veterinaria, 8: 01-07.

Talukder MMAA, Alam MM, Mohamed Y, Hassain MA (2005). Claw affection in dairy cows in an organized dairy farm. Bangladesh J ournal of Veterinary Medicine, 3: 110-113.

Thrusfield MV (2005). Criteria for Success of Questionnaire, In: Veterinary Epidemiology. $3^{\text {rd }}$ edition, Oxford, UK: Blackwell Science, $\mathrm{P}$ 189-213.

van der Waaij EH, Holzhauer M, Ellen E, Kamphuis C, de Jong G (2005). Genetic parameters for claw disorders in Dutch dairy cattle and correlation with conformation traits. Journal of Dairy Science, 88: 36723678.

Vanegas J, Overton M, Berry SL, Sischo WM (2006). Effect of Rubber Flooring on Claw Health in Lactating Dairy Cows Housed in Free-Stall Barns. Journal of Dairy Science, 89: 4251-4258.

Vokey FJ, Guard CL, Erb HN, Galton DM (2001). Effects of alley and stall surfaces on indices of claw and leg health in dairy cattle housed in a free-stall barn. Journal of Dairy Science, 84: 2686-2699. 